\title{
Polymer Chemistry
}

\section{CORRECTION}

View Article Online

View Journal I View Issue

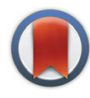

CrossMark

\&lick for updates

Cite this: Polym. Chem., 2017, 8, 946

\section{Correction: Amphiphilic and double hydrophilic block copolymers containing a polydehydro- alanine block}

Mark Billing, ${ }^{a, b}$ Grit Festag, ${ }^{a, b}$ Peter Bellstedt ${ }^{a}$ and Felix H. Schacher ${ }^{\star a, b}$

DOI: $10.1039 / c 7 p y 90013 a$

rsc.li/polymers block' by Mark Billing et al., Polym. Chem., 2017, DOI: 10.1039/c6py02076c.

The authors regret the errors in Scheme 1 in the original manuscript. The corrected version of Scheme 1 for this paper is shown below.

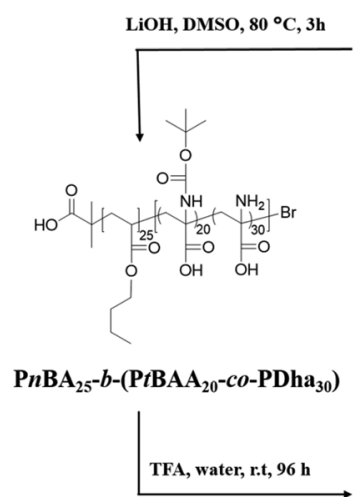

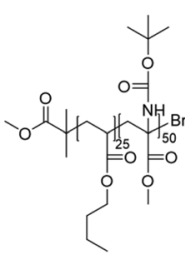

$\mathrm{PnBA}_{25}-b-\mathrm{PtBAMA}_{50}$

TFA, $\mathrm{CD}_{2} \mathrm{Cl}_{2}, 50^{\circ} \mathrm{C}, 1 \mathrm{~h}$
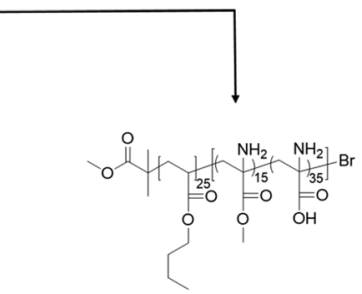

$\mathrm{PnBA}_{25}-b-\left(\mathrm{PAMA}_{15}-\mathrm{co}-\mathrm{PDha}_{35}\right)$

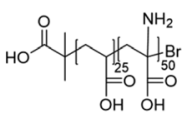

PAA $_{25}-b-$ PDha $_{50}$

Scheme 1 Structure of $\mathrm{PnBA}_{25}-b-\mathrm{PtBAMA} \mathrm{A}_{50}$ and the resulting block copolymers after the respective deprotection steps.

The Royal Society of Chemistry apologises for these errors and any consequent inconvenience to authors and readers.

${ }^{a}$ Laboratory of Organic Chemistry and Macromolecular Chemistry, Friedrich-Schiller-University Jena, Humboldtstraße 10, D-07743 Jena, Germany. E-mail: felix.schacher@uni-jena.de

${ }^{b}$ Jena Center for Soft Matter (JCSM), Friedrich-Schiller-University Jena, Philosophenweg 7, D-07743 Jena, Germany 